\title{
Factors associated with the quality of life of elderly caregivers of other elderly persons
}

Letícia Decimo Flesch' (ID)

Samila Sathler Tavares Batistoni',2 ${ }^{1 D}$ Anita Liberalesso Neri' ${ }^{1 D}$ Meire Cachioni ${ }^{1,2} \mathbb{D}$

\section{Abstract}

Objective: To evaluate the association between the double vulnerability of being elderly and a caregiver and quality of life assessed by Control, Autonomy, Self-realization and Pleasure factors (CASP-19). Method: 148 elderly caregivers participated in the present study. They were selected for convenience from Brazilian public and private health services - a sample from the study "The Psychological Well-Being of Elderly Persons Caring for Other Elderly Persons in a Family Context". The variables: caregiver's state of health, care demands, perception of burden, self-rated health, and quality of life were selected. Descriptive analyses, chi-squared tests, Fisher's exact test, the Kruskal-Wallis test and analysis of multivariate hierarchical logistics were carried out, with the Stepwise criteria applied for selection of variables. Results: The hierarchical multivariate analyses found that number of symptoms and total burden were significantly associated with a poorer quality of life. Elderly persons with three or more symptoms and those with a high burden level were at a higher risk of poor quality of life. The variables number of diseases, burden, and self-rated health compared with the past, were significantly associated with a poorer quality of life. Conclusion: It can be concluded that for the elderly caregiver, physical aspects (signs and symptoms, chronic diseases and a perception of health deterioration) combined with burden are the aspects that most influence quality of life.

\footnotetext{
1 Universidade Estadual de Campinas, Faculdade de Ciências Médicas, Programa de Pós-graduação em Gerontologia. Campinas, São Paulo, Brasil.

2 Universidade de São Paulo, Escola de Artes, Ciências e Humanidades, Curso de Graduação em Gerontologia. São Paulo, SP, Brasil.
}

Financing: Coordenadoria de Aperfeiçoamento de Pessoal do Ensino Superior (CAPES), through PhD scholarship (reference ${ }^{\circ} 1271787$ )

Keywords: Caregivers. Elderly. Quality of Life. Health Vulnerability. 


\section{INTRODUCTION}

Available literature on informal caregivers is wideranging, emphasizing the importance of studies of caregivers in the context of population aging ${ }^{1-3}$. However, one consequence of population aging remains little investigated: the growing number of elderly persons who are caregivers of other elderly individuals. This caregiver profile deserves attention, as the elderly are more vulnerable due to their biological frailty and are more prone to the development of chronic diseases ${ }^{4-6}$. Caregivers of the elderly, in turn, are also vulnerable to suffering possible burden from their activities and responsibilities, and to social isolation ${ }^{7-10}$. The elderly caregiver therefore suffers double vulnerability, needing to deal with the requirements of care and their own health needs at the same time.

A meta-analysis performed by Pinquart and Sorensen ${ }^{11}$ found that elderly caregivers have worse physical health than their younger counterparts. In considering psychological aspects, the study by Borg and Hallberg ${ }^{12}$ of caregivers aged 50-89 years found that life satisfaction declined as age increased. However, Chow and $\mathrm{Ho}^{13}$ studied caregivers of spouses aged 55 and above and found that elderly caregivers scored significantly lower in emotional and social distress, negative feelings, and depression. Despite this, they presented greater subjective well-being.

In this context, the Control, Autonomy, SelfRealization and Pleasure (CASP-19) scale emerged from the need for an instrument that evaluated quality of life in a form that was theoretically based and specific to the elderly. This instrument consists of four domains: control, autonomy, self-actualization and pleasure. The scale was developed on the basis of Maslow's Basic Needs Theory, which understands that quality of life should be assessed as the degree to which human needs are met ${ }^{14}$.

The study by Di Novi et al. ${ }^{15}$ which used a sample from the first two phases of the Survey of Health, Ageing and Retirement in Europe (SHARE) study, carried out in 11 European countries, used the CASP19 scale to compare caregivers and non-caregivers aged 50 and over. The authors divided the sample into three groups (northern Europe, southern Europe and continental Europe), according to public expenditure on long-term care. The results revealed the cultural complexity of informal care, as there were differences between caregivers and non-caregivers in total CASP-19 results and scores for the factors of the scale. These data show that socio-cultural differences influence the perception of the quality of life of caregivers; requiring, therefore, that care is taken when comparing studies from different regions of the world and the adequacy of the instruments and forms of the studies.

Rafnsson et al. ${ }^{16}$ analyzed 6,784 participants from the first three phases of the English Longitudinal Study of Aging (ELSA) to prospectively investigate the impact of transitions in informal care on the emotional well-being of the elderly. The results showed that in comparison with non-caregivers, caregivers of spouses or parents had lower CASP19 scores at baseline and after a follow-up period. Participants who were not caregivers at baseline but who cared for a spouse or their parents two years later, as well as those who continued with the status of caregiver, had deteriorating CASP-19 scores.

In this context, the CASP-19 instrument has been found to be effective in several surveys, some of which ${ }^{17,18}$ have suggested working with factors other than those initially proposed. It is important to note that, although the scale has exhibited good internal consistency in several studies, the relationship between the items has demonstrated variability. This seems to be related to the specific characteristics of each population. These specificities need to be better explored for a more detailed understanding of the phenomenon. In a previous study with this sample ${ }^{19}$, an association was established between double vulnerability and quality of life assessed by CASP-19.

The objective of the present study was to evaluate the association between double vulnerability (i.e. of elderly caregivers) and quality of life assessed by the factors of the CASP-19 scale, seeking a better understanding of this relationship through an evaluation of the disassembling of CASP-19 into factors. The model chosen was that developed by 
Neri et al. ${ }^{18}$, who performed a semantic-cultural validation of the scale for Brazilian adults and elderly persons. In addition, the authors performed factorial analysis and identified two models, with three and two factors, respectively. The proposal of this study was to prioritize the similarity between samples and to use the two factor model (factor 1, evaluating pleasure and autonomy and factor 2, related to autonomy and control with negative connotations), as this is the only study that performed factorial analysis of the instrument with a Brazilian sample.

\section{METHOD}

Data were collected from October 2014 to September 2015 and are taken from the study "Psychological Well-Being of Elderly Persons Who Care for Other Elderly Persons in a Family Context" carried out at the Faculty of Medical Sciences of the Universidade Estadual de Campinas, São Paulo, Brazil. The project employed a descriptive crosssectional design and aimed to analyze the effects of providing care on the physical and mental health of the caregiver, based on the stress and coping model proposed by Pearlin et al. ${ }^{20}$. From this database, sociodemographic variables (age, gender, date of birth, schooling, marital status and paid work), satisfaction with quality of life needs, selfassessment of health, perceived burden, the physical measurements of the caregiver and the degree of physical and cognitive dependence of the elderly recipient of care were selected for the present study.

Sample size was calculated based on the correlations between quality of life and the coping measures investigated in the study. The Pearson correlation coefficient method was used, with Fisher's transformation, considering a level of significance of $1 \%$, a test power of $90 \%$, a null correlation of 0.10 and a minimum correlation of 0.40 , resulting in the need to evaluate 140 caregivers.

The sample consisted of 148 people aged 60 years and older who informally cared for other elderly persons with some type of physical or cognitive impairment. They were recruited on a convenience basis in public and private health services in cities in southeastern Brazil, namely Jundiaí (38.5\%), Indaiatuba (29.1\%), Campinas (18.2\%) and Vinhedo $(14.2 \%)$, all of which are in the state of Sao Paulo.

The exclusion criterion applied was a score below the cut-off point of the Cognitive Abilities Screening Instrument - Short Form (CASI-S) validated for Brazil by Damasceno et al. ${ }^{21}$. The cutoff point for cognitive deficit is 23 for elderly persons aged 60 to 69 years and 20 for elderly persons aged 70 years and over.

Initially, the project was submitted to and approved by the Research Ethics Committee of the Universidade Estadual de Campinas (opinion: 822.364/2014). Participants were then invited to take part in the survey at the health service where the elderly care recipient received treatment. After signing a Free and Informed Consent Form, the research protocol, which lasted approximately one hour, was applied. The interviews were carried out at the health service or at home, when it was not possible for the caregiver to remain at the health service. Conducting interviews at the health service was authorized by the health professionals responsible through a printed document. Seven trained interviewers conducted the interviews at locations and times previously agreed upon with the participants.

The interviews were conducted in two parts. The first contained questions about the socioeconomic variables of the caregiver and their family, the cognition of the elderly care recipient, and the health conditions of the participants. The second part consisted of evaluations of the physical, psychological and social conditions inherent to the provision of care, family functionality, the health conditions and functionality of the care recipient, a subjective evaluation of care burden, subjective well-being, coping, and a self-assessment of health. After the interview the participants were offered a booklet with instructions on how to facilitate communication with the elderly. The instruments used are described in Chart 1.

Descriptive analysis was performed to describe the profile of the sample. Chi-squared and Fisher's exact tests were used to compare the categorical variables. The Kruskal-Wallis test was performed to 
compare the numerical variables between the three groups. After this test was applied, Dunn's post-hoc multiple comparisons test was used to identify the differences in the pairs. To analyze the association between the independent variables and quality of life, multivariate hierarchical logistic regression analysis was used, with a Stepwise variable selection criterion. The level of significance was $5 \%$.

Chart 1. Variables of interest and instruments used in study. Campinas, São Paulo, 2015.

\begin{tabular}{|c|c|}
\hline Variables of interest & Instruments \\
\hline $\begin{array}{l}\text { Socioeconomic conditions } \\
\text { of caregiver }\end{array}$ & $\begin{array}{l}\text { Questions related to the characteristics of the caregiver: age, gender, date of birth, } \\
\text { schooling, marital status and whether they perform paid work. The items in this block } \\
\text { were tested in the Fibra Study }{ }^{22} \text {. }\end{array}$ \\
\hline Physical health of caregiver & $\begin{array}{l}\text { Evaluated by a list of self-reported diseases, based on the question: Has a doctor ever told } \\
\text { you that you have the following diseases? A list of signs and symptoms that have occurred in } \\
\text { the last } 12 \text { months. The list of signs and symptoms was based on that used in the SABE } \\
\text { Study } y^{23} \text { and replicated in the Fibra Stud }{ }^{22} \text {. The measure of frailty validated by Nunes } \\
\text { et al. }{ }^{24} \text { was also used, according to the criteria of Fried et al. } .^{25} \text {. This consists of five } \\
\text { questions about weight loss, reduced strength, reduced physical activity, walking speed } \\
\text { and fatigue. These measures are answered in a dichotomous manner. }\end{array}$ \\
\hline Self-assessment of health & $\begin{array}{l}\text { Contains a five-point question on how the participant evaluates their overall health, } \\
\text { another on how they evaluate health care, a three-point question on how they evaluate } \\
\text { their health compared to a year ago, and one on how they evaluate their health } \\
\text { compared to other people of the same age. Suggested by Bowling }{ }^{26} \text { and tested in the } \\
\text { Fibra Study }{ }^{22} \text {. }\end{array}$ \\
\hline $\begin{array}{l}\text { Characteristics of elderly } \\
\text { care recipient }\end{array}$ & $\begin{array}{l}\text { Age, main health problem, if caregiver resides with the elderly care recipient, if caregiver } \\
\text { is the main and/or sole person responsible for them. }\end{array}$ \\
\hline $\begin{array}{l}\text { Degree of dependence of } \\
\text { elderly care recipient in } \\
\text { IADLs and BADLs* }\end{array}$ & $\begin{array}{l}\text { Brazilian version of the Lawton and Brody scale }{ }^{27,28} \text { : evaluates telephone use, } \\
\text { transportation, shopping, preparing food, performing household chores, using } \\
\text { medication and handling money. The respondent states whether, for each of the actions, } \\
\text { they are independent, need help or are totally independent. } \\
\text { Katz et al. }{ }^{29} \text { scale validated for the Brazilian population by Lino et al. }{ }^{30} \text {. Evaluates the } \\
\text { following activities: bathing, dressing, using the toilet, transference, continence and } \\
\text { food. The caregiver indicates if the patient needs partial or total help or does not need } \\
\text { help for each of these activities }\end{array}$ \\
\hline $\begin{array}{l}\text { Cognitive dependence of } \\
\text { elderly care recipient }\end{array}$ & $\begin{array}{l}\text { Clinical Dementia Rating (CDR): assesses cognitive impairment through six categories: } \\
\text { memory, orientation, judgment or problem solving, community relations, home or } \\
\text { leisure activities, and personal care. Each category is classified according to the degree } \\
\text { of impairment (no change, questionable, mild, moderate and severe). This evaluation is } \\
\text { performed through an interview with a person close to the patient. }\end{array}$ \\
\hline $\begin{array}{l}\text { Satisfaction in quality of } \\
\text { life needs }\end{array}$ & Composed of 19 items answered through a four point Likert type scale (CASP-19) ${ }^{14}$. \\
\hline Caregiver burden & $\begin{array}{l}\text { An instrument consisting of } 22 \text { questions, with answers given through a five-point } \\
\text { scale. It was developed by Zarit et al } .^{31} \text { and translated and validated for the Brazilian } \\
\text { population by Scazufca }{ }^{32}(\alpha=0.87) \text {. The study by Bianchi }{ }^{33} \text { carried out a factorial analysis } \\
\text { of the scale and found three factors. Factor } 1 \text { is the domain related to the perception } \\
\text { of stresses attached to the role, Factor } 2 \text { is the domain of perception of intrapsychic } \\
\text { tensions, Factor } 3 \text { can be interpreted as the domain related to the presence or absence of } \\
\text { competence and negative expectations related to care. }\end{array}$ \\
\hline
\end{tabular}

* IADLs: instrumental activities of daily living; BADLs: basic activities of daily living. 


\section{RESULTS}

The participants were aged between 60 and 86 years old, with a mean age of $69.8( \pm 7.1)$ years. The majority were women $(77 \%)$ and had between 0 and 4 years of schooling (87\%), while $51 \%$ were the sole caregiver. Regarding the care recipient, $62 \%$ were spouses, $28 \%$ offspring and $10 \%$ other family members, and the mean age was $81( \pm 9.8)$ years.

Tables 1 and 2 show the results of the comparisons of the categorical and numerical variables between the terciles of the quality of life factor scores and the results of the hierarchical logistic regression analysis for worsening in quality of life factor 1 and quality of life factor 2 . There was a significant difference between the terciles of the quality of life factor 1 score and the number of symptoms (a greater frequency of three or more symptoms in caregivers with worse quality of life), frailty (greater frequency of frail caregivers in those with worse quality of life), Zarit burden scale total and factor scores (greater frequency of greater degree of burden in those with worse quality of life), and subjective evaluation of current health and health compared with the past (greater frequency of worse subjective assessment of current health and health compared with the past in caregivers with worse quality of life).

There was also a significant difference between the terciles of the quality of life factor 2 score based on gender (greater frequency of women in caregivers with worse quality of life), number of diseases (greater frequency of three or more diseases in caregivers with worse quality of life), Zarit burden scale total and factor scores (greater frequency of greater degree of burden in caregivers with worse quality of life), and subjective health assessment (greater frequency of regular health with worse quality of life). 


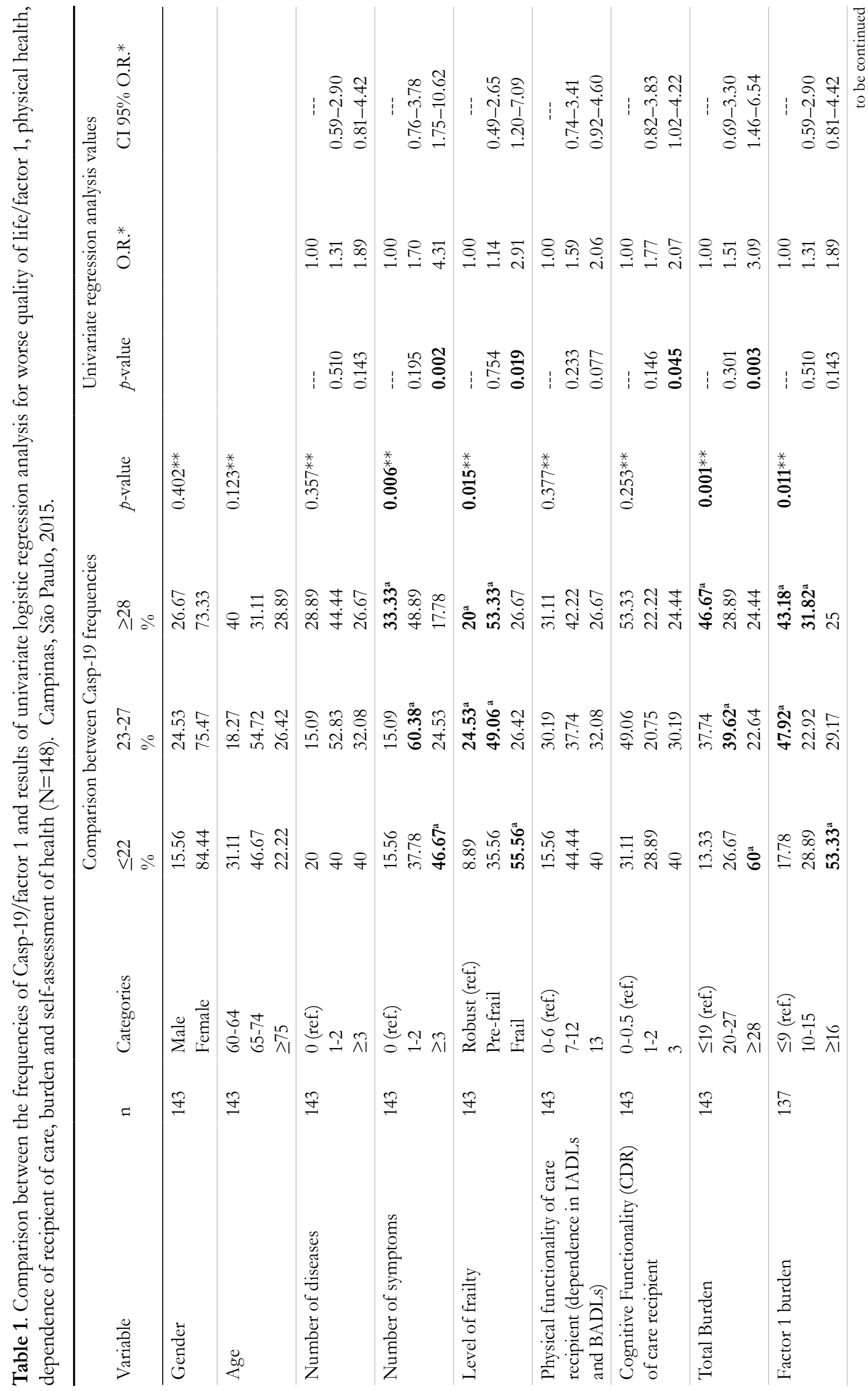




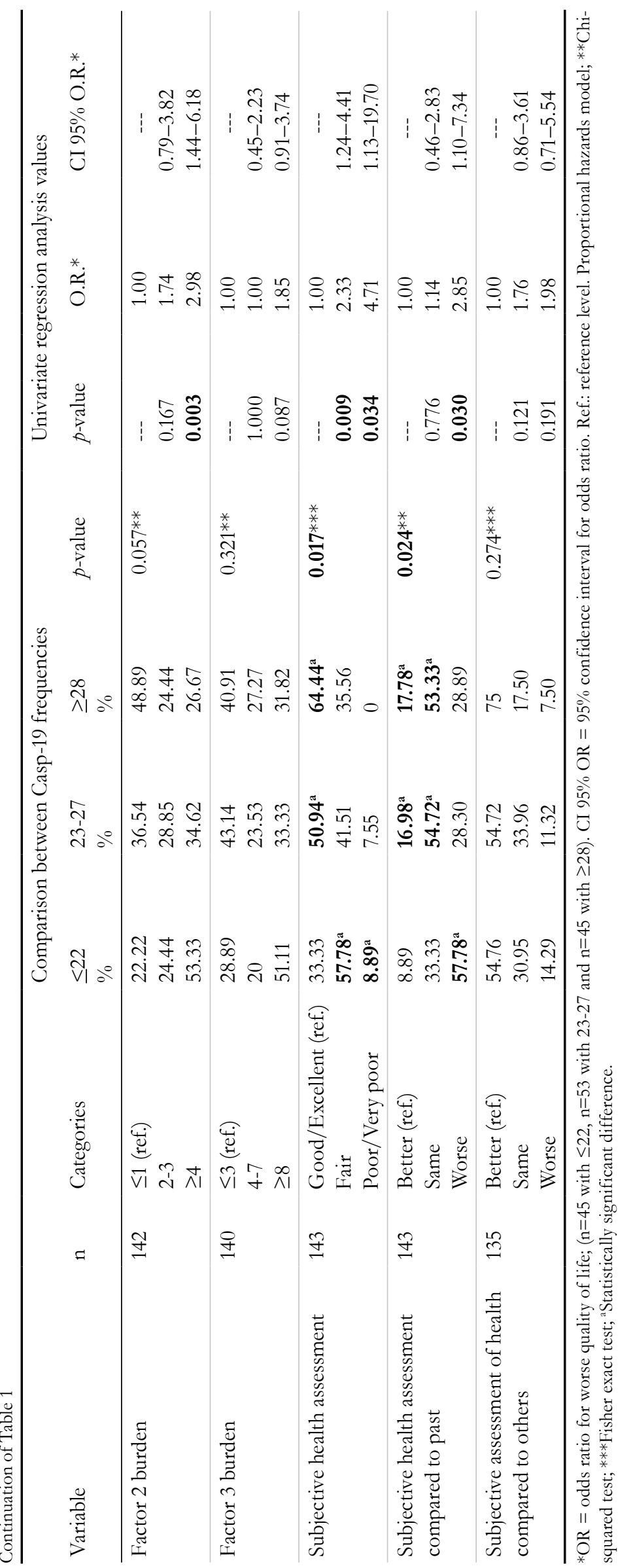




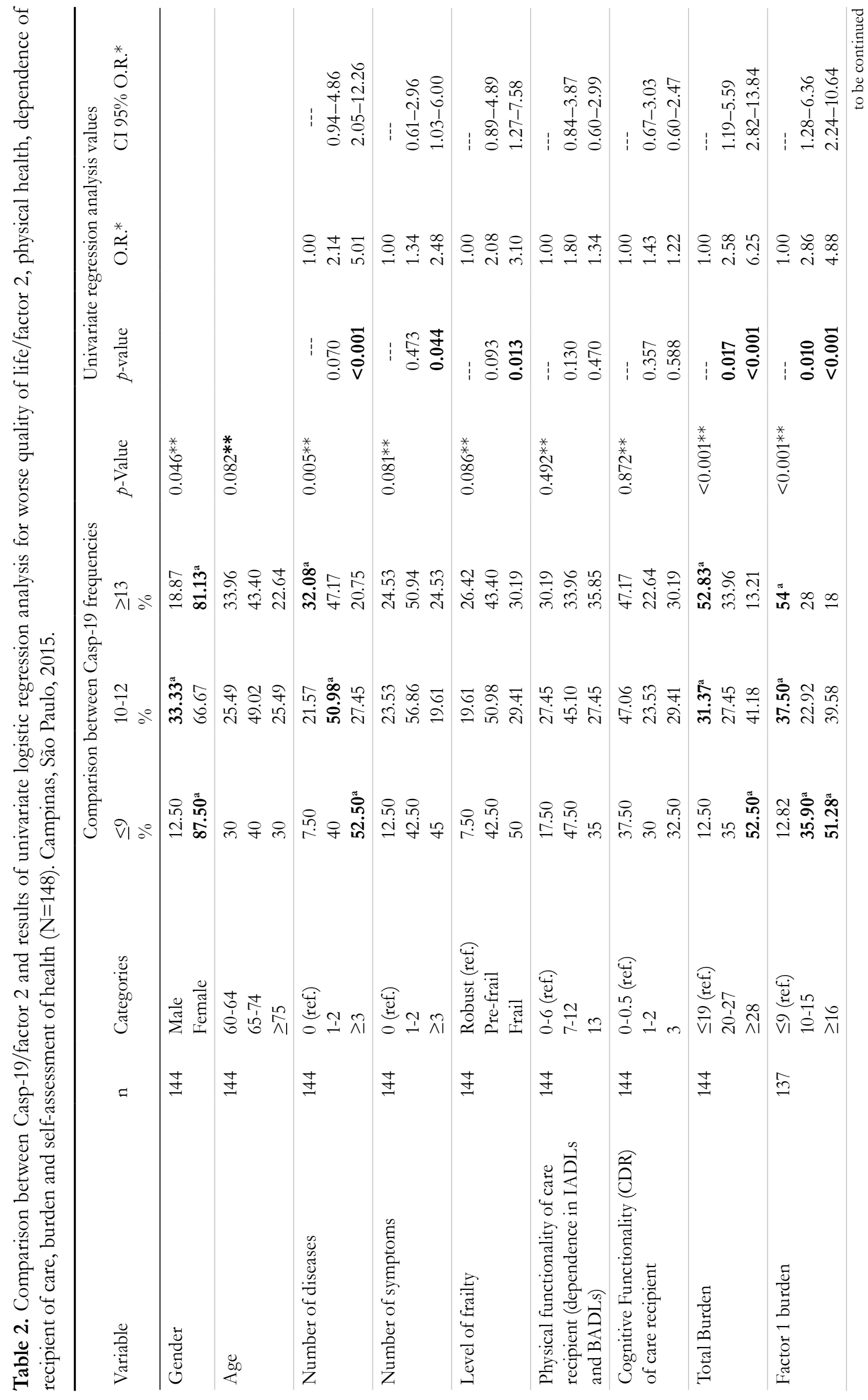




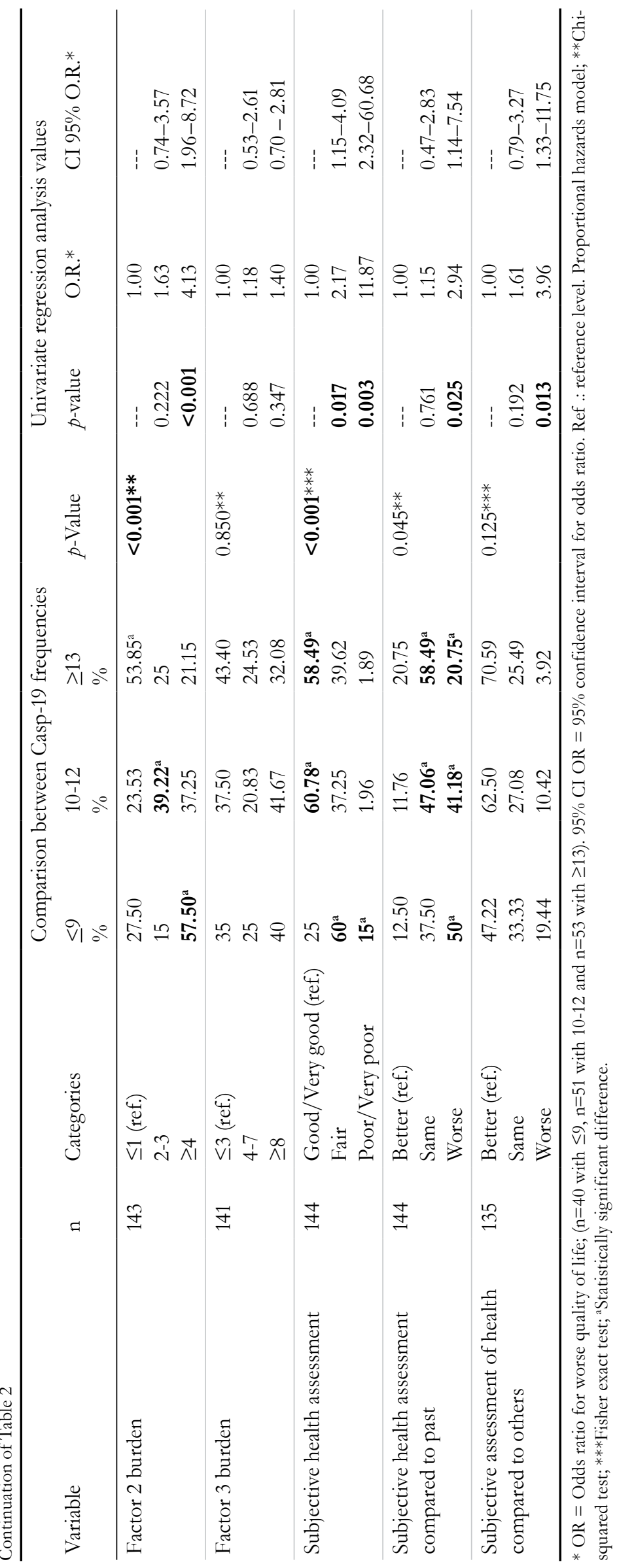


In the hierarchical multivariate analyzes, the number of symptoms and total burden were significantly associated with poorer quality of life in the factor 1 score. The elderly persons with the highest risk of a worse quality of life were those with three or more symptoms (3.0 times greater risk), and a high degree of burden (5.9 times greater risk). The variables number of diseases, burden factor 2 and subjective assessment of health compared with the past were significantly associated with a worse quality of life in the factor 2 score. The elderly with the highest risk of a worse quality of life were those with three or more diseases (5.0 times greater risk), those with a high degree of factor 2 burden (6.0 times greater risk), and a worse assessment of health compared with the past (4.9 times greater risk).

\section{DISCUSSION}

Despite its different dimensions, burden was the most significant variable in determining quality of life. For factor 1, total burden remained in the model. For factor 2 , only burden-factor 2 remained in the final model.

Factor 1 is more related to issues of pleasure and self-realization, or how one perceives one's life. This association was expected because, although perceived burden was associated with objective issues related to care, such as the degree of dependence of the care recipient and hours dedicated to care ${ }^{34,35}$, it was also related to the variables quality of life and well-being of the caregiver ${ }^{36,37}$.

Factor 2 is more closely related to control and autonomy, especially in relation to external factors. Contador et al. ${ }^{38}$ evaluated the burden of informal caregivers of patients with dementia and verified that aspects related to control (self-efficacy and contingency) most explained burden. In this study, only factor 2 burden, which concerns intrapsychic tensions, remained in the final model.

Regarding caregiver health, having more signs and symptoms of disease was associated with a worse factor 1 quality of life, while chronic diseases were associated with factor 2 quality of life. Although signs and symptoms are directly related to physical health, studies have shown that the manifestation of symptoms does not occur in the same way for all subjects. The perception of symptoms is related to attention to internal states, mood, cognition and environment ${ }^{39}$.

Thus, exhibiting more signs and symptoms of disease and perceiving greater burden was associated with lower quality of life in the pleasure and selfrealization dimension; and the presence of more chronic diseases, perception of declining health and more intrapsychic stresses related to care were associated with lower quality of life in the control and autonomy dimension.

In general, the health of the caregiver (signs and symptoms, chronic diseases and perception of poor health) and perceived burden were the aspects most associated with quality of life. However, the degree of physical and cognitive dependence of the care recipient did not prove very important for this association. These data suggest that for the elderly caregiver, their health and how they perceive the burden of care influence quality of life more than the dependencies of the elderly care recipient.

Although it provides advances in our theoretical knowledge of elderly persons who care for other elderly persons, the present study has limitations. As it did not use a representative sample, the results cannot be extended to the entire population of elderly caregivers in Brazil.

\section{CONCLUSION}

When the two factors are considered it can be concluded that, for elderly caregivers, aspects of physical health (signs and symptoms, chronic diseases and perception of worsening of health), together with burden, most influence the quality of life of this type of caregiver.

The objective conditions of care (degree of physical and cognitive dependence of the care recipient) did not appear to be relevant to the caregiver's quality of life, contrary to the findings of other studies. Perhaps because of their age, the health of the caregiver is more important than the dependence of the care recipient. 
Further studies on the elderly who informally care for other elderly persons are recommended. It is important to carry out research that tests

\section{REFERENCES}

1. Moral-Fernández L, Frías-Osuna A, Moreno-Cámara S, Palomino-Moral PA, del-Pino-Casado R. Primeros momentos del cuidado: el proceso de convertirse en cuidador de un familiar mayor dependiente. Aten Primaria. 2018;50(5):282-90.

2. Nunes DP, Brito TRP de, Corona LP, Alexandre T da S, Duarte YA de O. Elderly and caregiver demand: proposal for a care need classification. Rev Bras Enferm. 2018;71(suppl 2):844-50.

3. van Dam PH, Achterberg WP, Caljouw MAA. Care-Related Quality of Life of Informal Caregivers After Geriatric Rehabilitation. J Am Med Dir Assoc. 2017;18(3):259-64.

4. Boccolini CS, Camargo AT da SP. Morbimortalidade por doenças crônicas no Brasil: situação atual e futura. Rio de Janeiro: Fundação Oswaldo Cruz; 2016.

5. Mino-León D, Reyes-Morales H, Doubova SV, PérezCuevas R, Giraldo-Rodríguez L, Agudelo-Botero M. Multimorbidity Patterns in Older Adults: An Approach to the Complex Interrelationships Among Chronic Diseases. Arch Med Res. 2017;48(1):121-7.

6. Stenholm S, Westerlund H, Head J, Hyde M, Kawachi I, Pentti J, et al. Comorbidity and Functional Trajectories From Midlife to Old Age: The Health and Retirement Study. J Gerontol A Biol Sci Med Sci. 2015;70(3):332-8.

7. Ajay S, Kasthuri A, Kiran P, Malhotra R. Association of impairments of older persons with caregiver burden among family caregivers: Findings from rural South India. Arch Gerontol Geriatr. 2017;68:143-8.

8. Ringer T, Hazzan AA, Agarwal A, Mutsaers A, Papaioannou A. Relationship between family caregiver burden and physical frailty in older adults without dementia: a systematic review. Syst Rev [Internet]. 2017 [cited 2018 Aug 23];6(1). Available from: http://systematicreviewsjournal.biomedcentral. com/articles/10.1186/s13643-017-0447-1

9. Moon H, Townsend AL, Whitlatch CJ, DilworthAnderson P. Quality of Life for Dementia Caregiving Dyads: Effects of Incongruent Perceptions of Everyday Care and Values. The Gerontologist. 2016;38(1):57-62. interventions with this specific population, in order to propose improvements to the quality of life of these caregivers.

10. Alshammari S, Alzahrani A, Alabduljabbar K, Aldaghri A, Alhusainy Y, Khan M, et al. The burden perceived by informal caregivers of the elderly in Saudi Arabia. J Fam Community Med. 2017;24(3):145-50.

11. Pinquart M, Sörensen S. Correlates of physical health of informal caregivers: a meta-analysis. J Gerontol B Psychol Sci Soc Sci. 2007;62(2):126-37.

12. Borg C, Hallberg I. Life satisfaction among informal caregivers in comparison with non-caregivers. Scand J Caring Sci. 2006; 20: 427-38.

13. Chow EO-w, Ho HCY. Caregiver strain, age, and psychological well-being of older spousal caregivers in Hong Kong. J. Soc. Work. 2015; 15(5):479-97.

14. Hyde M, Wiggins RD, Higgs P, Blane DB. A measure of quality of life in early old age: The theory, development and properties of a needs satisfaction model (CASP-19). Aging Ment Health. 2003;7(3):186-94.

15. Di Novi C, Jacobs R, Migheli M. The Quality of Life of Female Informal Caregivers: From Scandinavia to the Mediterranean Sea. Eur J Popul. 2015;31(3):309-33.

16. Rafnsson SB, Shankar A, Steptoe A. Informal caregiving transitions, subjective well-being and depressed mood: Findings from the English Longitudinal Study of Ageing. Aging Ment Health. 2015; 24;1-9.

17. Hyde M, Higgs P, Wiggins RD, Blane D. A decade of research using the CASP scale: key findings and future directions. Aging Ment Health. 2015;19(7):571-5.

18. Neri AL, Borim SA, Cachioni M, Rabelo DF, Fontes AP, Yassuda MS. Nova validação semântico-cultural e estudo psicométrico da CASP-19 em adultos e idosos brasileiros. Cad. Saúde Pública. 2018; 34(10): e00181417

19. Flesch LD, Batistoni, SST, Neri, AL, Cachioni, M. Idosos que cuidam de idosos: dupla vulnerabilidade e qualidade de vida. Paideia (Ribeirão Preto). No prelo 2019.

20. Pearlin LI, Mullan JT, Semple SJ, Skaff MM. Caregiving and the stress process: an overview of concepts and their measures. The Gerontologist. 1990;30(5):583-94. 
21. Damasceno A, Delicio AM, Mazo DFC, Zullo JFD, Scherer P, Ng RTY, et al. Validation of the Brazilian version of mini-test CASI-S. Arq Neuropsiquiatr [Internet]. 2005 Jun [cited 2016 Aug 17];63(2b). Available from: http://www.scielo.br/scielo. php?script $=$ sci_arttext\&pid $=$ S0004-282X200500030 0010\&lng $=$ en\&nrm=iso\&tlng $=$ en

22. Neri AL, Yassuda MS, Moura JG de A, Araújo LF, Siqueira MEC, Santos GA, et al. Metodologia do Estudo Fibra Unicamp sobre fragilidade em idosos em Belém, Parnaíba, Campina Grande, Poços de Caldas, Ermelino Matarazzo, Campinas e Ivoti. In: Neri AL, editor. Fragilidade e qualidade de vida na velhice Dados do Estudo Fibra em Belém, Parnaíba, Campina Grande, Poços de Caldas, Ermelino Matarazzo, Campinas e Ivoti. Campinas: Alínea; 2013.

23. Lebrão ML, Duarte YA de O, Pan American Health Organization, editors. O Projeto SABE no município de São Paulo: uma abordagem inicial. 1a ed. Brasília, DF, Brasil: Organização Pan-Americana de Saúde, OPAS/OMS; 2003.

24. Nunes DP, Duarte YA de O, Santos JLF, Lebrão ML. Screening for frailty in older adults using a selfreported instrument. Rev Saúde Pública. 2015;49:1-9.

25. Fried LP, Tangen CM, Walston J, Newman AB, Hirsch C, Gottdiener J, et al. Frailty in older adults: evidence for a phenotype. J Gerontol A Biol Sci Med Sci. 2001;56(3):M146-156.

26. Bowling A. Measuring health: a review of quality of life measurement scales. 3. ed. Maidenhead: Open Univ. Press; 2005.

27. Lawton MP, Brody EM. Assessment of older people: self-maintaining and instrumental activities of daily living. The Gerontologist. 1969;9(3):179-86.

28. Brito FC, Nunes MI. Multidimensionalidade em Gerontologia II: Instrumentos de avaliação. In: Netto MP, editor. Tratado de Gerontologia. São Paulo: Atheneu; 2007.

29. Katz S, Ford AB, Moskowitz RW, Jackson BA, Jaffe MW. Studies of illness in the aged. The index of adl: a standardized measure of biological and psychosocial function. JAMA. 1963. 21;185:914-9.
30. Lino VTS, Pereira SRM, Camacho LAB, Ribeiro Filho ST, Buksman S. Adaptação transcultural da Escala de Independência em Atividades da Vida Diária (Escala de Katz). Cad Saúde Pública. 2008;24(1):103-12.

31. Zarit SH, Reever KE, Bach-Peterson J. Relatives of the Impaired Elderly: Correlates of Feelings of Burden. The Gerontologist. 1980;20(6):649-55.

32. Scazufca M. Brazilian version of the Burden Interview scale for the assessment of burden of care in carers of people with mental illnesses. Rev Bras Psiquiatr [Internet]. 2002 Mar [cited 2016 Aug 17];24(1). Available from: http://www.scielo. $\mathrm{br} /$ scielo.php?script $=$ sci_arttext\&pid $=$ S151644462002000100006\&lng=en\&nrm=iso\&tlng=en

33. Bianchi M. Indicadores de sobrecarga, estratégias de enfrentamento e sintomas depressivos em idosos que cuidam de outros idosos. [Campinas]: Unicamp; 2015.

34. Fuhrmann AC, Bierhals CCBK, Santos NO dos, Paskulin LMG. Association between the functional capacity of dependant elderly people and the burden of family caregivers. Rev Gaúcha Enferm. 2015;36(1):14-20.

35. Adelman RD, Tmanova LL, Delgado D, Dion S, Lachs MS. Caregiver Burden: A Clinical Review. JAMA. 2014;311(10):1052.

36. Rodríguez-Pérez M, Abreu-Sánchez A, Rojas-Ocaña MJ, del-Pino-Casado R. Coping strategies and quality of life in caregivers of dependent elderly relatives. Health Qual Life Outcomes [Internet]. 2017 Jan [cited 2018 Aug 23];15(1). Available from: http://hqlo. biomedcentral.com/articles/10.1186/s12955-017-0634-8

37. IşIk K, Erci B. Life Satisfaction and Care Burden of Caregivers Who Provide Care at Home to Elderly Patients and the Inflfluencing Factors. Turk Klin J Nurs Sci. 2018;10(1):11-7.

38. Contador I, Fernández-Calvo B, Palenzuela DL, Miguéis S, Ramos F. Prediction of burden in family caregivers of patients with dementia: A perspective of optimism based on generalized expectancies of control. Aging Ment Health. 2012;16(6):675-82.

39. Ogden J. Health psychology: a textbook. 5th edition. Maidenhead: Open University Press; 2012. 